\title{
THE ALTERATION IN SIZE OF THE NORMAL OPTIC DISC CUP*
}

\author{
BY \\ RANSOM PICKARD
}

EXETER

IN 1920 a paper (a) was read by me before the Ophthalmic Section of the Royal Society of Medicine in which it was deduced, from the sizes of the optic disc cups at different ages, that the cup normally increased in size with age. In another paper, read before the South Western Ophthalmological Society in $1935(b)$ at Bath, a diagram was exhibited showing increases actually observed. In the present paper 234 eyes, observed for a period of fifteen years or nearly so will be compared with 280 eyes, observed contemporaneously with the fifteen year group, but observed only once, and not included in that group. Finally these two groups are combined together, and a general rule as to the average growth deduced.

All the discs recorded were normal in appearance. Cases of cataract were included if the discs were sufficiently clear to be drawn. Similarly small corneal nebulae were included. All other forms of disease in the eyes were excluded. There were no cases of abnormal congenital conditions in these series.

The method of recording was that devised by me in 1920 and practised by me since then. The outline of the disc is drawn of its apparent size. The outline of the cup at the surface of the disc is then drawn of its apparent size and in its proper position. Similarly the outline of the bottom of the cup is drawn. Usually the outlines of the surface and the bottom of the cup are connected by three or four lines. This last detail is unessential, but to my eye they serve to link up the two cup outlines together. Finally a note is made of the depth of the cup in dioptres. In the case of cups where the cup is larger at the base than on the surface, a bracket is made outside the disc margin at the place where this is so, and "bulbous" written there.

To estimate the size of the cup a transparent grid is used. The apparent size of the disc and of the cup surface are found, and the size of the cup expressed as a percentage of the disc.

The question of error in the estimate arises. No opportunity has occurred to compare my results with those of another observer on the same cases. It is estimated that there should not be more than five per cent. error in drawing the disc outlines, and two per cent. in measuring with the grid. This is sufficiently close for clinical purposes.

* Received for publication, November 8, 1947. 
At the outset it must be pointed out that there are great variations from the average in the sizes, both at the first record and the subsequent occasions, in all age groups. This will be seen in the tables, where they vary from 5 to 100 per cent. And the possible variations are large. If the case of an initial cup varying from 5 to 50 , and the final from 51 to 100 be considered the possible variations would be 2,250, which represents the maximum. And the number of eyes-234-multiplied into this will give an idea of the possibilities. Nevertheless, as happens in large collections, the actual cups cluster around the average.

Fifteen year group.-This consists of 234 eyes, observed for fifteen years or more, except for five, one of which was observed for fourteen years, and four between fourteen and fifteen years. For these extrapolation was employed, at the last observed rate of growth; it being thought that for so few cases and for so short a time, the total figures would not be vitiated.

TABLE I

Fifteen Year Groups

\begin{tabular}{|c|c|c|c|c|c|c|c|c|c|}
\hline \multicolumn{2}{|c|}{$\begin{array}{c}\text { Age } \\
\text { Groups }\end{array}$} & \multirow{2}{*}{ 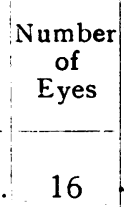 } & \multirow{2}{*}{$\begin{array}{c}\begin{array}{c}\text { Average } \\
\text { Initial } \\
\text { Cups } \\
\%\end{array} \\
23\end{array}$} & \multirow{2}{*}{$\frac{c_{\text {Initial }}}{\text { Maxima }}$} & \multirow{2}{*}{\begin{tabular}{|c|}
$\begin{array}{c}\text { Initial } \\
\text { Minima }\end{array}$ \\
5
\end{tabular}} & \multirow{2}{*}{$\begin{array}{c}\text { Cups } \\
\text { at } \\
10 \text { yrs. } \\
\\
39\end{array}$} & $\begin{array}{l}\text { Slope o } \\
10 \mathrm{yrs}\end{array}$ & $\begin{array}{l}\text { Cups at } \\
15 \mathrm{yrs} .\end{array}$ & $\begin{array}{l}\text { Total Slope } \\
\text { at } 15 \text { yrs. }\end{array}$ \\
\hline$-10 y$ & rrs. & & & & & & $1 \cdot 6$ & 45 & $1 \cdot t$ \\
\hline $11-20$ & ", & 22 & 22 & 61 & 7 & 44 & $2 \cdot 2$ & 48 & $1 \cdot 7$ \\
\hline $21-30$ & , & 30 & 24 & 53 & 8 & 41 & 1.6 & 52 & $1 \cdot 9$ \\
\hline $31-40$ & , & 62 & 26 & 48 & 5 & 43 & $1 \cdot 7$ & 53 & $1 \cdot 8$ \\
\hline $41-50$ & , & 60 & 23 & 59 & 7 & 49 & $2 \cdot 6$ & 59 & $2 \cdot 3$ \\
\hline $51-60$ & ", & 30 & 28 & 57 & 8 & 52 & $2 \cdot 2$ & 66 & $2 \cdot 5$ \\
\hline $61-70$ & , & 14 & 28 & 50 & 13 & 45 & $1: 7$ & 60 & $2 \cdot 1$ \\
\hline & & & & & Avera & S Sl & 1.9 & & $1 \cdot 9$ \\
\hline
\end{tabular}

Table I gives a summary of these eyes. The group clusters around early middle age, for about this time that the social circumstances tend to be more stabilised, and patients are more likely to persist in coming to the same oculist.

As will be seen later, the averages for the early years are rather 
high, those for the later too low. The irregularity in the maximum initial cups should be noted; that for the $11-20$ years is 61 , the highest in the fifteen year group.

The slope is the percentage growth per year of the cups. It is an important measurement, for by this the rate of increase of the cups is ascertained, and the various cups compared with each other. Thus, the ten year group, derived from the fifteen year group by subtracting the growth of the last five years, is found by the slope to have the same value, $1 \cdot 9$, as the fifteen year group. This means that the average increase for the whole term is unaltered; although the individual cups differ from each other.

TABLE II

Alteration of slope (percentage increase of cups per year). Ten year group extracted from the fifteen year group.

Figures in brackets are the number of eyes in the various sub-groups.

\begin{tabular}{|c|c|c|c|c|c|c|c|}
\hline \multirow{2}{*}{$\begin{array}{l}\text { Cup size } \\
\text { sub-groups }\end{array}$} & \multicolumn{7}{|c|}{ Year Groups } \\
\hline & -10 & $11-20$ & $21-30$ & $31-40$ & $41-50$ & $51-60$ & $61-70$ \\
\hline $1-10$ p.c. & $2 \cdot 9(2)$ & $3 \cdot 2(2)$ & $2 \cdot 9(5)$ & $2 \cdot 5$ (9) & $3.8(7)$ & $4^{\circ} 6(1)$ & 一 \\
\hline $11-20$ & $1 \cdot 5(4)$ & $2 \cdot 9(12)$ & $2 \cdot 6(11)$ & $2 \cdot 5(15)$ & $25(19)$ & $24(7)$ & $25(7)$ \\
\hline $21-30$ & $1.7(6)$ & $1 \cdot 4(4)$ & $1 \cdot 0(3)$ & $1 \cdot 5(26)$ & $2 \cdot 1(24)$ & $2 \cdot 3(7)$ & $0.0(1)$ \\
\hline $31-40$ & $0.7(3)$ & $1.5(1)$ & 0.9 (4) & $1 \cdot 5(10)$ & $199(6)$ & $2 \cdot 1(13)$ & 0.6 (3) \\
\hline $41-50$ & $1 \cdot 7(1)$ & $0.2(2)$ & $1 \cdot 3(6)$ & 0.6 & $0 \%$ (1) & $1 \cdot 1 \quad(2)$ & $14(4)$ \\
\hline $51-60$, & - & - & 0.6 (1) & - & $0^{\circ} 0$ (1) & - & - \\
\hline $61-70$, & - & $0.3(1)$ & - & - & - & - & -- \\
\hline
\end{tabular}

An interesting condition is seen if the various age classes are separated out according to their cup sizes. In Table II this has been summarised in the slopes for the various values. With seven exceptions, the slopes have arranged themselves in such an order that the smaller initial cups have the higher slopes, the total number of the items being 37. Although some of the subgroups are quite small, the proportion of 30 to 7 is significant, all the more that the discrepancies, $0.2,1 \cdot 0,0 \cdot 1,0 \cdot 1,0.4,2.5$ and 0.8 , have among them three groups which each have cnly one eye.

This means that the smaller cups tend to catch up the larger, but they are only partially successful. The consistency of these cup 
groups is surprising and was unexpected. The smallness of some of the groups, a statistical disadvantage, is counterbalanced by the occurrence of this inverse order in all the seven age groups.

TABLE III

Single Observations-Ten Year Groups -40 eyes in each group.

\begin{tabular}{l|c|c|c|c}
\hline Year Groups & Average & Maxima & Minima & Slope \\
\hline $11-20$ & 17 & 49 & 6 & - \\
$21-30$ & 23 & 39 & 6 & 0.5 \\
$31-40$ & 26 & 65 & 9 & 0.3 \\
$41-50$ & 25 & 55 & 11 & 0.1 \\
$51-60$ & 31 & 75 & 17 & 0.6 \\
$61-70$ & 35 & 73 & 11 & 0.4 \\
$71-80$ & 45 & 95 & 9 & 1.0 \\
\hline
\end{tabular}

Single observations.- These consisted of 280 cups, in age groups of 40 each, seven groups in all, beginning at $11-20$ years. They are displayed in Table III. The averages for the groups show a steady rise from the first to the last. The maxima are not so regular, but show a fairly consistent order; the minima are more irregular, they show that in some patients the cups remain small to the end. The slope cannot be stated, as only single observations were made on each case. If the order of the successive groups be taken as the increase per ten years, it will be seen that this agrees fairly well with the average found for the combined group. This single observation group is a better sample than the fifteen year group, for the number in each age group is the same for all ages; in the fifteen year eyes the smallness of the numbers in the early and the late groups decreases their usefulness statistically, unavoidable as this is.

Combined Group. With the object of smoothing out the irregularities in the two groups, both were combined together. The ten year groups, from the fifteen year groups, were taken instead of the latter, to conform more easily with the single observation group, which is arranged in ten year groups. From this mixture an average was found, which is used for the final deduction of the average course of 
the disc growth. All the disc percentages thus obtained, their age groups being known, may be used, if they are kept in their proper age groups. The ten year cups will have to be included in the next batch to that from which they started. For instance, those derived from the 11-20 year group will have to be included in the 21-30 group for the purposes of this final estimate. Table IV shows the various averages as obtained from the separate groups, and the last set the average as obtained from their combination. (See Chart A).

\section{TABLE IV}

Average cups. Initial, ten year and single observations.

\begin{tabular}{|c|c|c|c|c|c|c|c|c|c|}
\hline & No. of eyes & -10 & $11-20$ & $21-30$ & $31-40$ & $41-50$ & $51-60$ & $61-70$ & $71-80$ \\
\hline Single observations... & 280 & - & 18 & 23 & 26 & 25 & 31 & 35 & 45 \\
\hline Fifteen year group & & & & & & & & & \\
\hline Initial cups & 234 & 23 & 22 & 24 & 26 & 23 & 28 & 28 & - \\
\hline Ten year cups $\ldots$ & 234 & - & 39 & 44 & 41 & 43 & 49 & 52 & 45 \\
\hline $\begin{array}{l}\text { Combined average } \\
\text { (Initial, } 10 \text { yr., and } \\
\text { single observations) }\end{array}$ & - & - & 23 & 29 & 29 & 31 & 36 & 41 & 45 \\
\hline
\end{tabular}

Average slope. The chart A exhibits the final combined average for the various age groups, they are shown as black dots. They are nearly in a straight line. If a straight line is drawn from 23 (11-20 yrs.) at a slope of 0.35 , it will cut the $71-80 \mathrm{yr}$. line at 44 , and, if this is prolonged to the left, as far as the $0-10$ column, it will cut it at $19 \cdot 5$. This is an average slope for the disc growth. The general formula is thus :- $-19.5+(0.35 \times$ age in years $)=$ Average cup for that particular year.

This formula must be taken for what it states, it is the average between the wide extremes of the maxima and the minima, as shown on Chart A. Nevertheless the nearly straight line shown by the actual figures shows that it is reliable as an average. The figures for the individual cases tend to group themselves around the averages, as should be the case if the latter are representative.

The practical point that follows is that any cup above 70 per cent. should be regarded as suspect, and be considered with the fields and tension before it can be said to be normal. It has seemed to me that a large cup cannot be accepted as physiological unless these precautions are taken. 


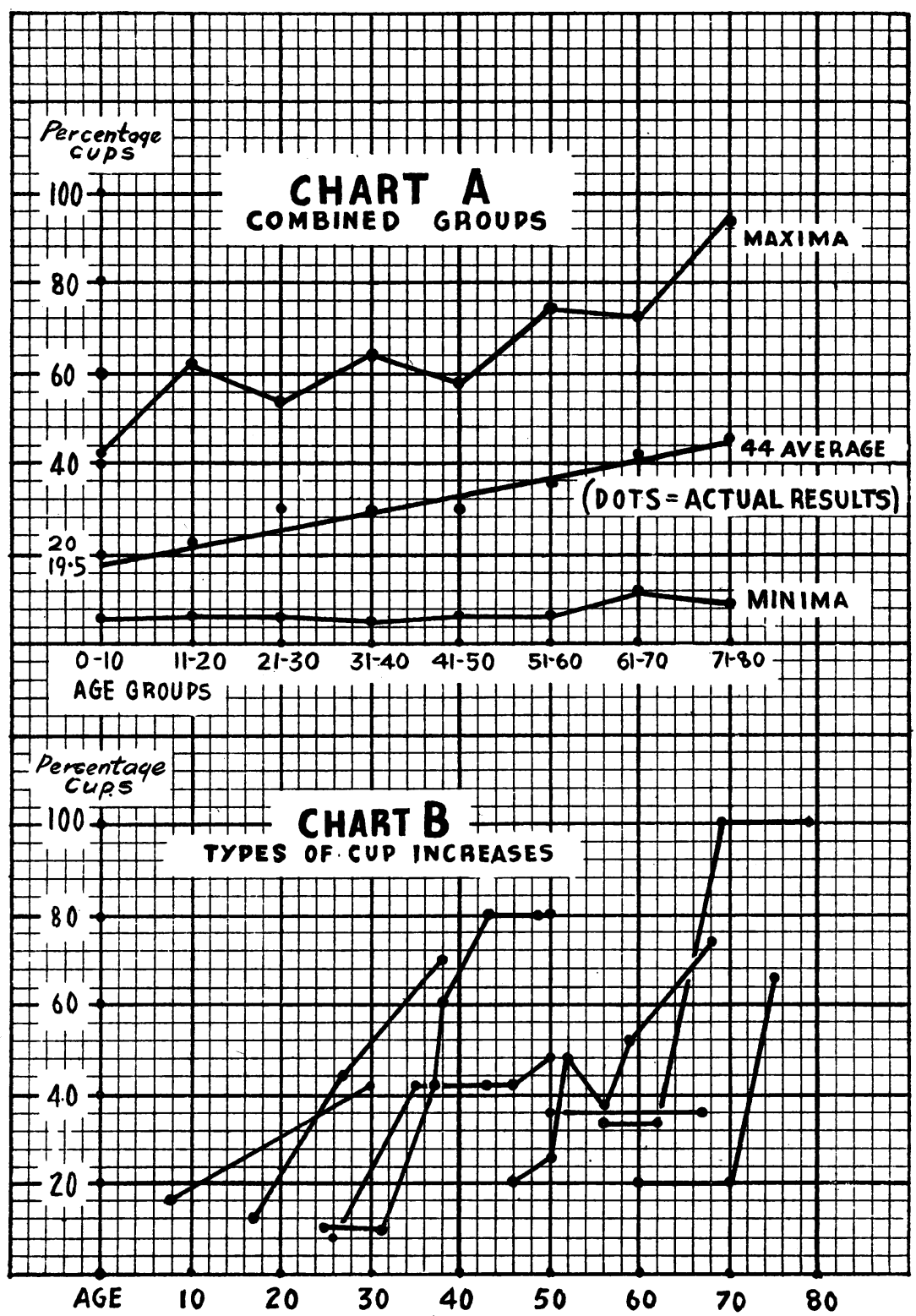


Decrease in the cups. In one eye the cup was 10 per cent. smaller at the end of fifteen years. Twelve others showed a decrease at some time, though all these were larger at the end of the fifteen years than at the beginning. These temporary losses were $3,3,4$, $5,5,6,6,6,7,10,10$, and 10 per cent.

One cup was stationary for the whole period, it was 36 per cent. Five others showed very small increases $3,3,4,5$, and 6 per cent.

It is not uncommon to have a period of arrest of growth of the cup. This may occur at any period, when first seen, during the increase, or towards the end; examples are given in Chart B, which gives types of cup changes. It will be seen that in some of these the record extends over more than fifteen yeais.

Depth of the cups. Increase in depth tends to happen with the enlargement of the cup area. but irregularly so. It may be stated as a generalisation that if a cup enlarges to 60 per cent., its depth will increase generally by 0.5 to 1.0 dioptres, but by no means invariably so. A disc may increase to 100 per cent. and yet retain a depth of $1.0 \mathrm{D}$. An increase to $3 \mathrm{D}$, with an enlargement of the cup percentage must be investigated by the field and tension.

It is not easy to find any one cause for the cup enlargement. In the early years it can be attributed to the natural growth of the body, but this cannot be the reason for the continuous enlargement which goes on after youth, after the body has stopped growing. It may be other influences come into play which cause the enlargement to continue, which cannot be considered as pathological. Our bodies are always undergoing change, which in ordinary terms would not be thought abnormal, and are considered as part of the processes which lead to old age, yet are not, in general terms, thought to be pathological, though in an exact sense, they are. Perhaps the cup enlargement should be so considered. But this is merely to place it in a group of effects which we do not understand, though well recognised as the approach of old age. In the case of the eye, however, these changes do not affect the attributes of sight, according to the standards applied in the routine of ordinary practice, nor vision as used in every day life. It must be acknowledged that this is an analogy rather than an explanation.

\section{REFERENCES}

(a) Proc. Roy. Soc. Med., Vol. XIV, 1921. Sect. Ophthal., pp. 31-38.

(b) Trans. Ophthal. Soc. U.K., Vol. LV; 1935. 